American Journal of Environmental Sciences 3 (3): 111-116, 2007

ISSN 1553-345X

(C) 2007 Science Publications

\title{
The Spatial-Temporal Variability of Nitrates in a Section of the Cuneo Plain (North West Italy)
}

\author{
Massimo Vincenzo Civita, Adriano Fiorucci, Bartolomeo Vigna \\ DITAG - Dipartimento del Territorio, dell'Ambiente e delle Geotecnologie \\ Politecnico di Torino - C.so Duca degli Abruzzi 24, 10129 - Torino, Italy
}

\begin{abstract}
The study of an aquifer system is very important, but also very complicated because of the high temporal and spatial variabilities of a system and because of the phenomena that are at play within the system. It is from these problems that the necessity arises of finding methods that are able to extend point knowledge to an entire area, while maintaining all the parameters that play a role, while starting from a limited amount of available information. It is therefore necessary to make use of a mathematical treatment of the data, assuming that each measurement point carries with it the information relative to a certain neighbourhood of an amplitude that has to be defined. Among the different methods that are available to interpolate data, the best are those of a geostatic nature that are based on a probabilistic approach and which allow models to be used that reflect the uncertainties of the characteristic parameters of an aquifer and on how the physical phenomena evolve as a whole. The first and most important step of a geostatic study is the characterisation of a spatial, temporal or spatial-temporal phenomenon. This present work falls into this ambit. It was carried out in a sector of the Cuneo Plain (NW Italy) where the spatial and temporal variability of nitrate concentrations was evaluated in a surface aquifer together with the hydro-chemical characteristics of the water resource under examination. The analysis of the nitrate concentrations showed that these increase going from $\mathrm{SW}$ to NE, in correspondence to the increase in human and zootechnical activities, that is, from the piedmont zones to the central zones of the plain according to the direction of the groundwater flow. From the data that were obtained, it results to be impossible to determine the quality of the groundwater resources in a definitive way because of the great variability of the phenomena and it is therefore necessary to identify a congruous number of measurement points with the purpose of describing, as accurately as possible, the state of the system in time, whilst also taking into consideration the economic aspects that such a proposal would involve
\end{abstract}

Keywords: Nitrates, pollution, Italy

\section{INTRODUCTION}

The ground water contamination by nitrate ions is a problem that has gradually become more serious, so much so that in some European countries there is the real risk of a catastrophe. This is basically due to the intensive changes that have taken place in agrozootecnical activities from semi-craftsman-like production to full industrial installations. Italy is not immune to these problems; it is in fact the fifth European producer or organic fertilisers and it has undergone an increase of $42 \%$ in the last fifteen years[1]. The Italian Government only put European Directive 91/676/CEE, relative to the protection of water from contamination by nitrates from agricultural sources, into force a few years ago through an adequate law (Legislative Decree 152/99 and subsequent modifications). A control of the quality of groundwater resources was thus imposed in order to mitigate the effects due to the use of nitrogen substances. This led to the proliferation of attempts to attain the requirements of the aforementioned regulation, attempts that did not always succeed in obtaining the desired results. The approach utilised in many of these attempts was too closely connected to an evaluation of the qualitative state of the water resources, but without taking into correct consideration the various hydrogeological and hydrochemical aspects that characterise this phenomenon.

This work shows how it is impossible to completely determine the quality of groundwater resources, because of the great variability of the phenomena, and to show the need to identify a congruous number of sampling points with the purpose of describing the state of the water system in time as accurately as possible, taking into consideration the economic aspects that such a proposal involves. An area in the Cuneo Plain (NW Italy) was chosen for this purpose (Fig. 1) where

Corresponding Author: Adriano Fiorucci, DITAG (Dipartimento del Territorio, dell'Ambiente e delle Geotecnologie) Politecnico di Torino, c.so Duca degli Abruzzi 24, 10129 - Torino, Italy 


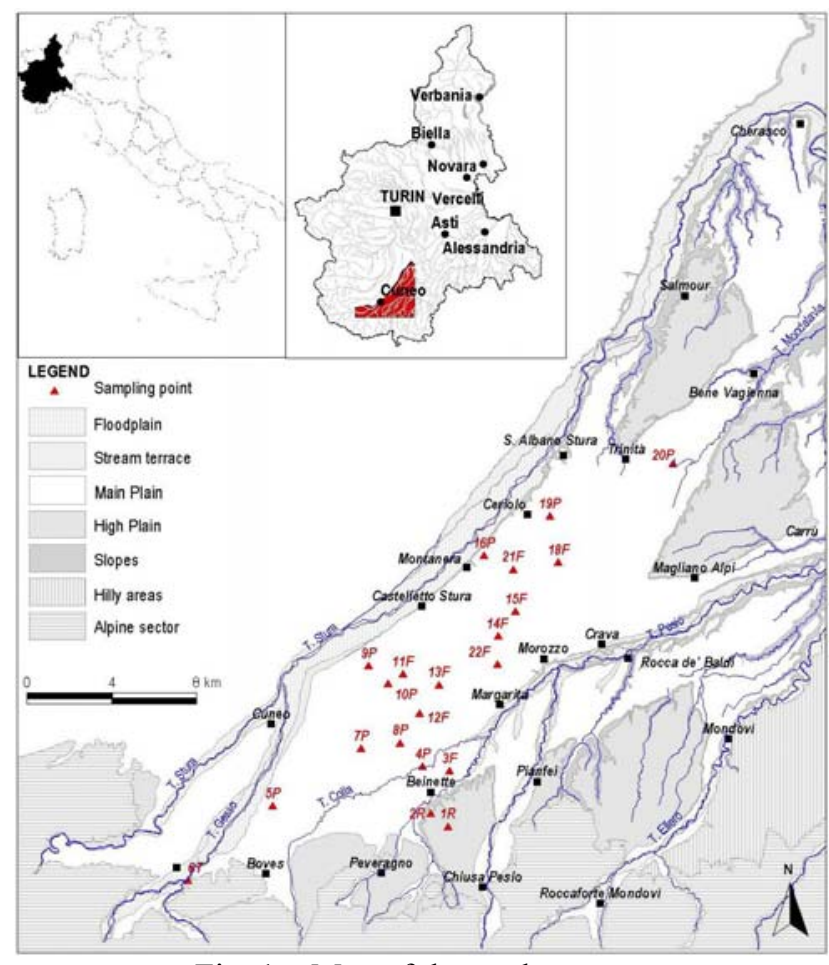

Fig. 1 - Map of the study area

the spatial and temporal variability of nitrate concentrations was measured in the water-table aquifer.

\section{Hydrogeological layout}

The examined area covers a surface of about $600 \mathrm{~km}^{2}$ and involves 24 municipalities in the Cuneo province. From a geographical point of view (Fig. 1), this area is bordered on the North and West by the Stura Stream and on the East by the Tanaro River, on the South East by the Ellero Stream and on the South by the Ligurian Alps. The plain on the right of the Stura is slightly sloping towards the North East and is characterised by deep fluvial incision (the Gesso, Pesio, Sogliola, Ellero, Mondalavia streams..) that further divides the plain into elements, some of which are completely isolated. The entire sector is connected to the Alpine reliefs through a series of piedmont highlands, known as the "high terraces" (Eula, Roracca, Peveragno, Pianfei and Beinette highlands), often with several orders of secondary scarps. The main plain is made up of a series of large adjacent fans formed through the migration of braided rivers at the mouth of the alpine valleys of the Ellero, Pesio, Gesso and Stura streams. The depths of the deposits of the main alluvial complexes vary from 40 to $80 \mathrm{~m}$ in the apical zone (the Boves area) and gradually reduces to $4-5 \mathrm{~m}$ in the most distal regions of the plain (Sant'Albano Stura, Magliano Alpi). The lithology of the complex is composed of sometimes rather coarse gravel, with slightly altered clasts and abundant sandy-slimy matrixes which correspond to the fluvioglacial and Riss fluvial geological units; a partially clayey soil with a mean thickness of one metre can be found throughout. The hydraulic conductivity values of the complex is rather high with values between $1.5 \mathrm{E}-0.3$ and $1.2 \mathrm{E}-4 \mathrm{~m} / \mathrm{s}$ [2].

The main plain houses a water-table aquifer fed by local precipitations, but above all be large losses from the streams coming from the alpine valleys. The Gesso Stream alone releases into aquifer more than $5 \mathrm{~m}^{3} / \mathrm{s}$ in the area below Boves [3]. An important contribution to the supply of the water-table aquifer comes from the losses of the main irrigation channels not provided of waterproofed beds, which cross most of the plain. Going from the apical zones towards the most distal areas, an inversion of setting can be observed: the water-table aquifer gradually tends to equally supply the streams through a series of springs and blowouts. The springs are mainly located along the slopes of the Stura and Pesio Streams, while the blowouts are instead spread throughout the plain playing an important role in this area. In the XI century the south-western part of Piedmont was, to a great extent, covered in woods with large swampy and marshy zones that had formed due to outcropping of the piezometric surfaces of the watertable aquifer. In the Cuneo Plain, the origin of these blowouts is conditioned both by the geometry of the aquifer (which gradually decreases in depth down the piedmont zone) and by the gradient of the piezometric surfaces, which is less than the dip of the topographic surfaces, and which in the intersection area between the two, causes the outcropping of the ground water. These swampy and malarial areas began to be reclaimed at the beginning of the XIII century through the excavation of draining ditches known as "Fossi colatori" (drainage ditches) or "Fontanili" (Springs).

There are numerous drainage ditches in the area under examination, in the zone $\mathrm{W}$ of Margarita, where a discharge of more than $1.8 \mathrm{~m}^{3} / \mathrm{s}$ were measured.

The piezometric disposition of the main water-table aquifer (Fig. 2), shows the presence of an ground water divide SSW of Castelletto Stura that separates the flow mainly coming from the losses of the Gesso Stream below Borgo San Dalmazzo, deviating part towards the NW and part in the NE direction which then supplies the blowouts.

Along the Castelletto Stura-Sant'Albano Stura line, a series of springs discharge a good half of the aquifer; the remaining part comes to the surface in the blowouts zone W of Margarita and Morozzo. Most of the losses from the Gesso Stream arrive directly to the important Beinette spring [4] through the understanding carbonate aquifer. Another equally conspicuous part of the losses from the Gesso Stream emerge North of Beinette (Paschi ditch with a flow of about $1 \mathrm{~m}^{3} / \mathrm{s}$ ). 


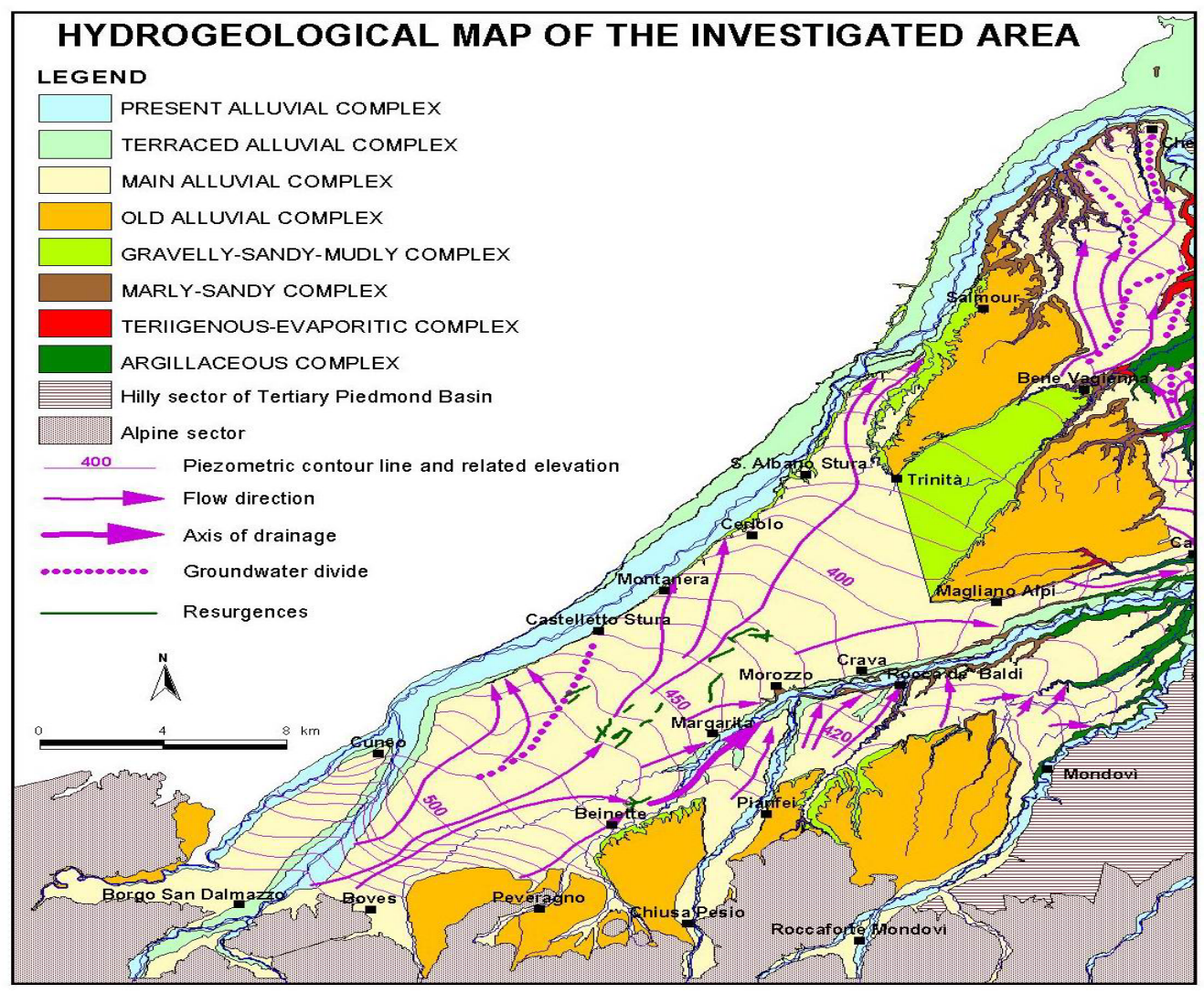

Fig. 2 - Hydrogeological map of the investigated area

nitrate ion

In the sector on the right of Pesio there are some subsectors that appear to be independent of each other. Some of these, the Beinette-Pianfei sub-set in particular, supply conspicuous blowouts.

\section{RESULTS AND DISCUSSION}

The data relative to the nitrate ion contents in the 21 sampling points for the ten sampling monthly campaigns (May 2004 - April 2005) are shown in Table 1.

The $1 \mathrm{R}$ and $2 \mathrm{R}$ samples refer to springs not fed by the aquifer under discussion (the Beinette and Rifreddo springs); these data should be considered for reference purposes. The 6T sample point is situated on the riverbed of the Gesso Stream in the area in which it supplies the aquifer. The mean nitrate ion content recorded for each sampling campaign relative to the samples concerning the aquifer highlight how the analysed water resources are seriously compromised even though still below the maximum admissible concentration (50 mg L ${ }^{-1}$; Legislative Decree 152/99, Ministerial Decree 31/2001). However, it should be pointed out that the mean value is generally not very significant and, in this particular case, considering the standard deviations that were obtained, it has no meaning whatsoever. contents in time is shown in Figure 3 for the various sampling points, with the exception of points 19P and 20P which have been reported separately in Figure 4 because of their high values which would make the variations of all the others less evident.

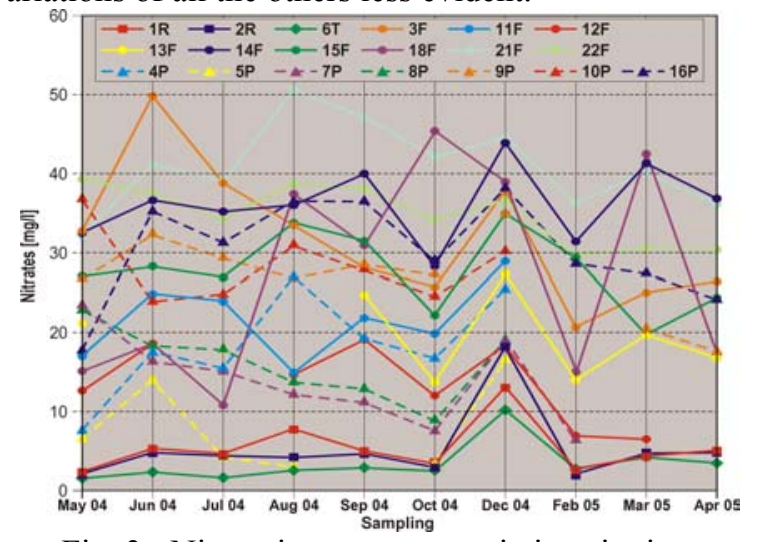

Fig. 3 - Nitrate ion contents variations in time

A variability in the data clearly emerges from the graphs and this clearly demonstrates the unreliability of the mean value and the different conditions of the samples obtained from the springs $(1 \mathrm{R}, 2 \mathrm{R})$ compared to those belonging to the aquifer, with the exception of the point relative to the Gesso Stream. 
Am. J. Environ. Sci., 3 (3): 111-116, 2007

Table 1 - Nitrate ion contents in the measurement points $\left(\mathrm{mg} \mathrm{L}^{-1}\right)$

\begin{tabular}{|c|c|c|c|c|c|c|c|c|c|c|c|}
\hline COD. & type & May 04 & Jun 04 & Jul 04 & Aug 04 & Sept 04 & Oct 04 & Dec 04 & Feb 05 & Mar 05 & Apr 05 \\
\hline $1 \mathrm{R}$ & spring & 2.33 & 5.29 & 4.60 & 7.72 & 4.98 & 3.35 & 13.00 & 2.58 & 4.79 & 5.04 \\
\hline $2 R$ & spring & 2.00 & 4.73 & 4.43 & 4.23 & 4.63 & 2.90 & 18.20 & 1.91 & 4.74 & 4.73 \\
\hline $3 F$ & blowout & 32.72 & 49.83 & 38.80 & 33.47 & 28.09 & 25.71 & 37.81 & 20.65 & 25.00 & 26.40 \\
\hline $11 \mathrm{~F}$ & blowout & 16.99 & 24.83 & 23.90 & 14.93 & 21.82 & 19.83 & 28.69 & & & \\
\hline $12 F$ & blowout & 12.64 & 18.58 & & 14.67 & 19.10 & 12.03 & 18.36 & 6.91 & 6.50 & \\
\hline $13 F$ & blowout & 21.15 & & 17.80 & & 24.68 & 13.68 & 27.36 & 13.97 & 19.69 & 16.73 \\
\hline $14 \mathrm{~F}$ & blowout & 32.51 & 36.62 & 35.20 & 36.01 & 40.00 & 28.31 & 43.89 & 31.42 & 41.31 & 36.87 \\
\hline $15 \mathrm{~F}$ & blowout & 27.08 & 28.31 & 26.90 & 33.75 & 31.48 & 22.17 & 34.92 & 29.39 & 19.73 & 24.37 \\
\hline $18 \mathrm{~F}$ & blowout & 15.11 & 18.57 & 20.80 & 37.43 & 30.94 & 45.40 & 38.95 & 15.00 & 42.50 & 17.22 \\
\hline $21 \mathrm{~F}$ & blowout & 32.18 & 41.17 & 39.00 & 50.60 & 47.07 & 42.10 & 44.55 & 36.25 & 40.11 & 36.10 \\
\hline $22 \mathrm{~F}$ & blowout & 39.31 & 37.48 & 34.30 & 38.74 & 38.07 & 34.12 & 36.53 & 29.54 & 30.57 & 30.37 \\
\hline $4 P$ & well & 7.77 & 17.66 & 15.70 & 27.17 & 19.43 & 16.93 & 25.63 & & & \\
\hline $5 P$ & well & 6.72 & 14.15 & 4.42 & 3.29 & & 3.56 & 16.76 & & & \\
\hline $7 P$ & well & 23.67 & 16.56 & 15.30 & 12.37 & 11.40 & 7.75 & 19.10 & 6.60 & & \\
\hline $\mathbf{8 P}$ & well & 23.04 & 18.54 & 18.10 & 13.95 & 13.10 & 9.14 & 19.24 & & & \\
\hline $9 P$ & well & 27.02 & 32.60 & 29.60 & 27.01 & 28.78 & 27.53 & 35.16 & & 20.71 & 17.83 \\
\hline $10 \mathrm{P}$ & well & 37.01 & 24.13 & 25.00 & 31.23 & 28.16 & 24.77 & 30.45 & & & \\
\hline $16 P$ & well & 17.94 & 35.44 & 31.50 & 36.65 & 36.72 & 29.27 & 38.39 & 28.84 & 27.64 & 24.37 \\
\hline 19P & well & 62.14 & 79.72 & 65.10 & 87.05 & 81.72 & 77.07 & 68.39 & 46.71 & 57.86 & 53.60 \\
\hline $20 P$ & well & 94.29 & 165.05 & 124.00 & & 149.87 & 182.09 & 68.31 & & & \\
\hline $6 \mathrm{~T}$ & river & 1.54 & 2.34 & 1.63 & 2.55 & 2.90 & 2.56 & 10.20 & 2.72 & 4.27 & 3.47 \\
\hline Average & & 27.94 & 36.75 & 31.50 & 29.46 & 36.30 & 32.84 & 33.82 & 22.33 & 27.99 & 26.12 \\
\hline Standard & Deviation & \pm 21.22 & \pm 36.26 & \pm 27.18 & \pm 20.04 & \pm 33.02 & \pm 40.11 & \pm 15.52 & \pm 13.52 & \pm 15.54 & \pm 13.20 \\
\hline
\end{tabular}

A difference can however be noted between the data obtained from the samples taken in the wells and those coming from the springs. This difference is shown in Figure 5 where the mean values obtained at the blowouts, the mean values of the wells and, for comparison purposes, the data for the springs and the Gesso Stream, are all shown for each sampling campaign.

This diagram illustrates how the nitrate ion contents average are generally higher in the wells than in the blowouts. This can be put down to the large volumes of water that emerge which favour a dilution process.
It should in fact be recalled that the presence of nitrate ions with concentrations above $5 \mathrm{mg} \mathrm{L}^{-1}$ should be considered due to an external origin and in particular to agro-zootechnical activities that involve the use of nitrogen compounds of animal (sewage) or inorganic (chemical fertiliser) origin.

From this it can be deduced that the nitrate ion should all in all be considered as an external contaminant and not as a natural component of the ground water. It is therefore subject to those dilution phenomena that are typical of contaminants. The only particular that makes nitrate ion different from all the other contaminants is its typical areal and not point distribution. In studies 
concerning the vulnerability of aquifers, manuring practices are considered a widespread source of danger.

These considerations lead us to consider that the study of groundwater contamination from nitrate ions must consider evaluations that deal with the areal distribution of the phenomenon.

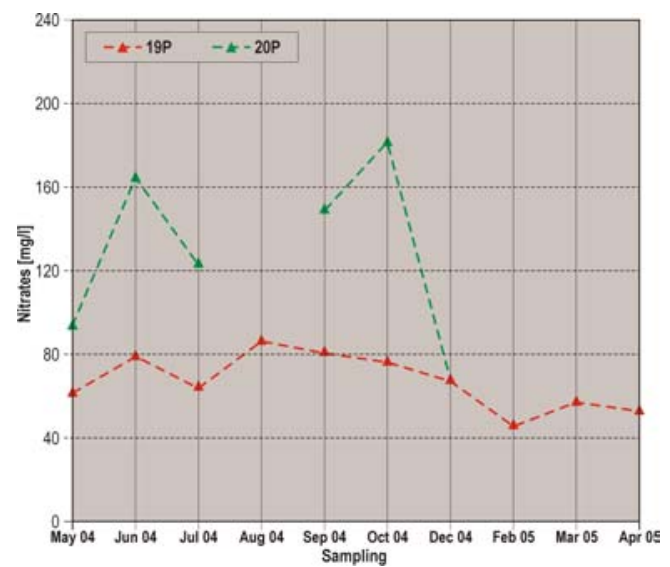

Fig.4 - Nitrate ion contents variations in time

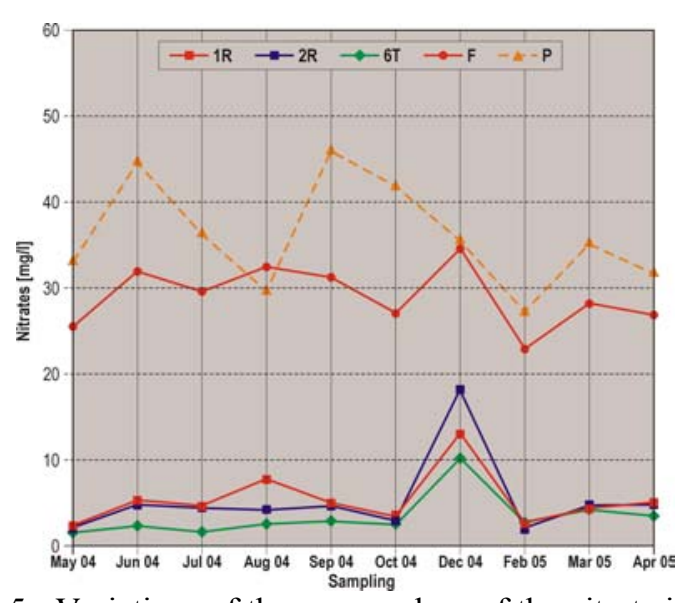

Fig.5 - Variations of the mean values of the nitrate ion contents

For this purpose, the kriging geostatic method was used to obtain a map of the isoconcentrations of nitrate ions relative to the May 2004, June 2004 and September 2004 measurement campaigns, which are shown in Figures 6, 7 and 8.

The common datum to the three sampling campaigns is the increase in the nitrate ion concentrations in the SWNW direction in accordance with the general trend of the underground flow (Figure 2).

The piedmont area, situated down-flow, is therefore less compromised by the phenomenon of contamination from nitrates. This could be due to a lower contamination load or a greater flow from the aquifer which would favour the dilution. However, both hypotheses are valid: the ago-zootechnical vocation of the whole area leads to the reasonable conclusion that the nitrogen manure loads on the aquifer are almost

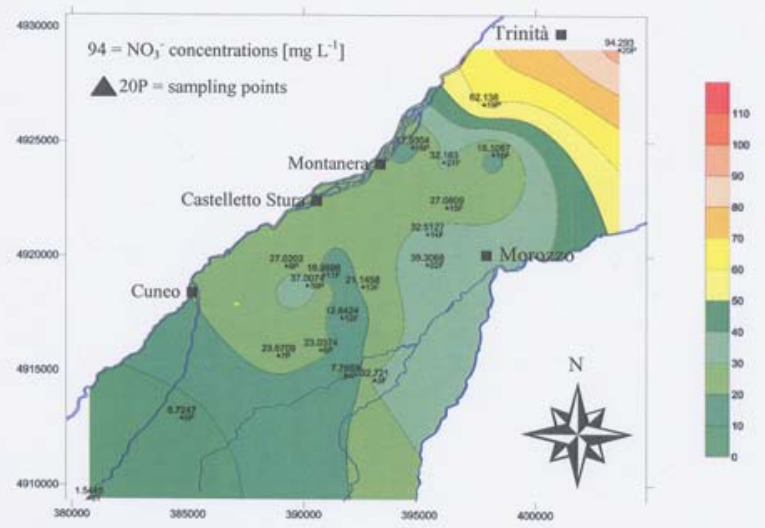

Fig. 6 - Isoconcentrations of the nitrate ions (sampled on May 26 2004)

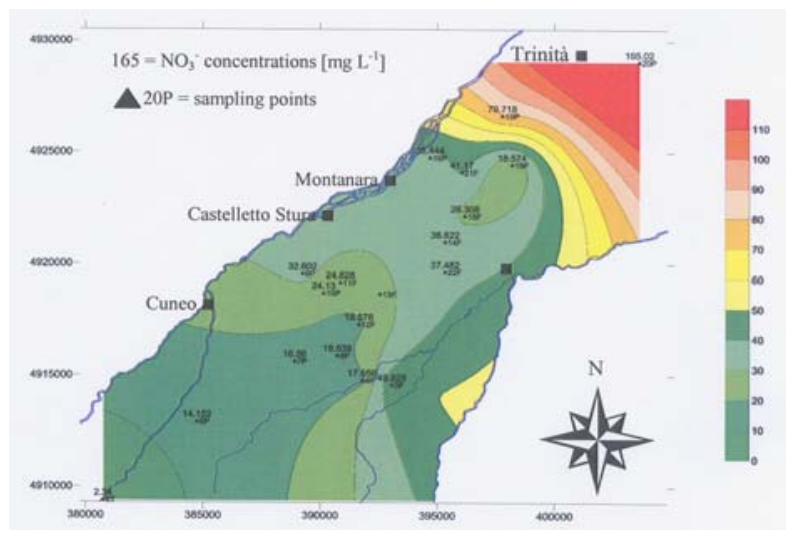

Fig. 7 - Isoconcentrations of the nitrate ions ( sampled on June 30 2004)

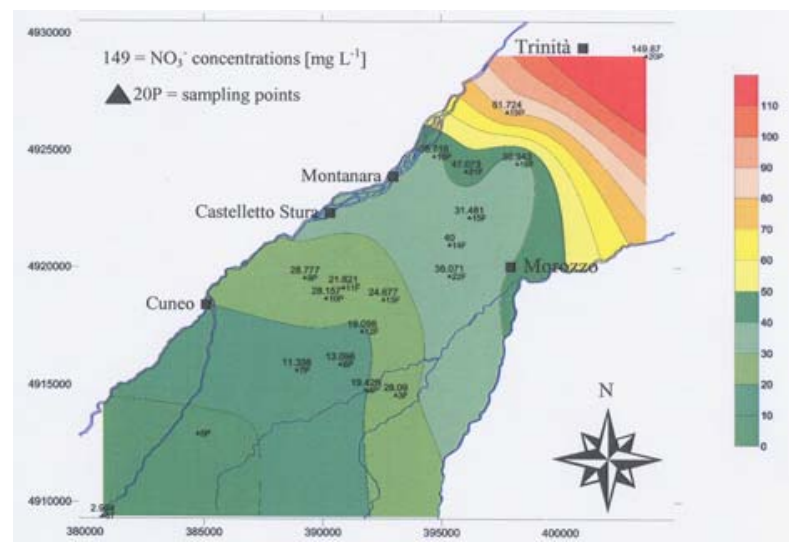

Fig. 8 - Isoconcentrations of the nitrate ions (sampled on 29 September 2004)

constant, therefore the large volumes of water, due to the reloading of the Gesso Stream, play a fundamental role in the contaminant dilution. It is, however, important to simply verify the load of nitrogen manures that is introduced during the agricultural practices as there is a tendency to only introduce sufficient nitrogen fertiliser for the agricultural practices, but at the same 
time an amount that is sustainable for the environment and in particular for the ground water.

The other values of nitrate ions observed in the northwestern sector of the area can be explained both as a normal increase in the contamination load (increase in fertilisation in the area) and as a progressive decrease in the flow and in the depth of the aquifer which remarkably prejudices the dilution capacity of the aquifer itself. Together with these considerations, it should be mentioned that the introduction of nitrogen into an aquifer is a phenomenon that assails areas of different extensions but it also depends on time, that is, on the defined fertilisation periods which can vary according to the type of cultivation.

Furthermore, the role played by the variation in the piezometric level should not be forgotten, in relation to the possibility of the periodically water-table aquifer making zones saturated where nitrogen fertilisers can precipitate during infiltration and stops in the unsatureted zone. Such fertilisers can be dissolved when the piezometric rising makes saturated the upper zone.

The data obtained have yet again shown that the knowledge of the hydrogeological situation of an area is essential and necessary to correctly evaluate the effect that the sometimes indiscriminate use of nitrogen fertilisers can have on ground water, a fundamental resource for a great variety of uses, among which potable uses stand out. It is just clear that a simple evaluation of the qualitative state of the groundwater resources is not sufficient to characterise the phenomenon as it is marked by spatial-temporal variations due to the times and areas of the introduction of the contaminant as well as the effects produced by the dynamics of the ground water and the structure of the aquifer itself. It is therefore necessary not to limit the whole evaluation to the assessment of vulneration (i.e. impact in the space and time) of a ground water sistem, but also to use suitable instruments to assess the contamination risk by nitrates. This allows a serious utilisation of the territory that can reconcile the policies of protecting the environment with the certainly not negligible requirements of the agricultural operators. In other words, this means finding a correct equilibrium between production and protection. A complex, but practicable, methodological approach has recently been proposed that uses a set of different methods prepared by research Line 4 of the National Group for the Defence against Hydrogeological Catastrophes (GNDCI) of the Italian National Research Council (CNR) with the purpose of obtaining a univocal evaluation of the contamination risk of aquifers by nitrates. This methodology arises from the synergetic application of the SINTACTS R5 method [5] used to evaluate the intrinsic vulnerability of aquifers to contamination, and the IPNOA method [6] which is a parametric index for the identification of areas vulnerable to contamination from nitrates. The research, which is still under way, has already supplied comforting results in some test sites [7] and has above all demonstrated how a programme based only on an evaluation of the vulnerability of the system can be disastrous, especially when such an evaluation is the result of a collection of data obtained from not adequately studied monitoring networks with the consequent incongruity with the system that has to be studied [8].

\section{ACKNOWLEDGEMENTS}

The authors would like to thank the Provincia di Cuneo and the Gestione Parchi e Riserve Naturali Cuneesi Organisation for their help and the Istituto di Istruzione Superiore Statale "G. Cigna" in Mondovi $(\mathrm{CN})$ for their precious collaboration.

\section{REFERENCES}

1. Communities. Rep. 600025001, Ultrecht, pp.80.

2. Civita M., Fiorucci A., Olivero G. e Vigna B., 2000. Le risorse idriche sotterranee del territorio Cuneese (Piemonte meridionale). GEAM dicembre 2000, parte 2 pp. 225-241.

3. Perrone E., 1916. Carta Idrografica d'Italia - Tanaro. Roma

4. Armando E., Civita M., Olivero G., Sambuelli L. e Vigna B., 1988. Identificazione di una struttura idrogeologica sepolta alimentante una notevole fonte di approvvigionamento idrico (sorgenti di Beinette Cuneo). Bollettino Associazione Mineraria Subalpina, XXV, n. 1, pp. 25-28.

5. Civita M. e De Maio M., 2000. Valutazione cartografia tematica della vulnerabilità degli acquiferi all'inquinamento con il sistema parametrico SINTACS R5. A new parametric system for the assessment and automatic mapping of ground water vulnerability to contamination. Quaderni di Tecniche di Protezione Ambientale, Sezione Protezione delle acque sotterranee, Pitagora Ed., Bologna, Vol. 72, pp. 226.

6. Padovani L. e Trevisan M., 2002. I nitrati di origine agricola nelle acque sotterranee. Quaderni di Tecniche di Protezione Ambientale, Sezione Protezione delle acque sotterranee, Pitagora Ed., Bologna, Vol. 75, pp. 103.

7. Civita M. e Fiorucci A., 2003. Vulnerazione e vulnerabilità degli acquiferi all'inquinamento da nitrati. Atti Conv. Internaz. "Sistemi agricoli e inquinamento da nitrati” Perugia, 11.12.2003 pp. 134 $-138$

8. Civita M. e Fiorucci A., 1999. Diagrammi di qualità delle acque sotterranee: aggiornamenti e discussioni. Atti del $3^{\circ}$ Convegno Nazionale sulla Protezione e Gestione delle acque sotterranee per il III millennio, pp.207-215. 